\title{
AS METODOLOGIAS ATIVAS COMO ESTRATÉGIAS PARA DESENVOLVER A INTERDISCIPLINARIDADE NO ENSINO MÉDIO
}

\author{
ACTIVE METHODOLOGIES AS STRATEGIES TO DEVELOP \\ INTERDISCIPLINARITY IN HIGH SCHOOL \\ METODOLOGÍAS ACTIVAS COMO ESTRATEGIAS PARA DESARROLLAR LA \\ INTERDISCIPLINARIDAD EN LA ESCUELA SECUNDARIA
}

\author{
Francisco Antônio de Sousa ${ }^{1}$, Marcelo Nunes Coelho*2 \\ ${ }^{1}$ Programa de Pós-Graduação em Ensino (POSENSINO-IFRN/UERN/UFERSA) \\ ${ }^{2}$ Programa de Pós-Graduação em Ensino (POSENSINO-IFRN/UERN/UFERSA)
}

* Correspondência: Rua Raimundo Firmino de Oliveira, 400, Conjunto Ulrick Graff, Mossoró-RN, CEP: 59.628330

Artigo recebido em 01/08/2019 aprovado em 01/04/2020 publicado em 04/08/2020.

\section{RESUMO}

O presente artigo tem como objetivo refletir acerca das contribuições e implicações das metodologias ativas no desenvolvimento da interdisciplinaridade no processo de ensino e aprendizagem. Foi realizada uma pesquisa bibliográfica de 18 produções científicas de quatro periódicos disponibilizados no Portal de Periódicos da CAPES, os quais foram avaliados com Qualis A1, A2, B1 e B2, e também dos anais do Simpósio Nacional de Ensino de Ciência e Tecnologia, tendo como recorte temporal o período de 2013 a 2018. Houve também uma categorização por meio da análise de conteúdo (BARDIN, 2011) na qual os trabalhos foram dissecados para perceber aproximações das metodologias ativas com a interdisciplinaridade. Como resultados, podemos destacar que as metodologias ativas contribuem para criar condições que potencializam o desenvolvimento da interdisciplinaridade, pois proporcionam, aos discentes, situações que permitam a vivência e busca pela construção do conhecimento por meio do processo de diálogo, intelectualmente estruturado, entre os mesmos e entre as áreas do saber. Contudo, apesar de sua inegável importância, práticas interdisciplinares ainda são muito incipientes e não acontecem, efetivamente, como ação pedagógica e essa realidade precisa ser transformada e para isso é necessário a realização de pesquisas cientificas que coloquem a prática da interdisciplinaridade como foco.

Palavras-chave: Metodologias Ativas. Interdisciplinaridade. Educação Básica.

\section{ABSTRACT}

This article aims to reflect on the contributions and implications of active methodologies in the development of interdisciplinarity in the teaching and learning process. A bibliographic search of 18 scientific Productions was made from four journals available on the CAPES Journals Portal, which were evaluated with Qualis A1, A2, B1 and B2, and also from the proceedings of the Simpósio Nacional de Ensino de Ciências e Tecnologia, was conducted, time frame from 2013 to 2018. There was also a categorization through content analysis (BARDIN, 2011) in which the works were dissected to perceive approximations of active methodologies with interdisciplinarity. As results, we can highlight that the active methodologies contribute to create conditions that potentiate the development of interdisciplinarity, because they provide the students with situations that allow the experience and search for the construction of knowledge through the process of dialogue, intellectually structured, between them. And between areas of knowledge. However, despite their undeniable importance, interdisciplinary practices are still very incipient and do not happen, effectively, as pedagogical action and this reality needs to be transformed and for this it is necessary to carry out scientific research that puts the practice of interdisciplinarity as a focus. 
Keywords: Active Methodologies. Interdisciplinarity. Basic education.

\section{RESUMEN}

Este artículo pretende reflexionar sobre las contribuciones e implicaciones de las metodologías activas en el desarrollo de la interdisciplinariedad en el proceso de enseñanza y aprendizaje. Se realizó una búsqueda bibliográfica de 18 producciones científicas de cuatro revistas disponibles en el Portal de Revistas CAPES, que se evaluaron con Qualis A1, A2, B1 y B2, y también de las actas del Simposio Nacional de Ciencia y Tecnología; dentro del marco temporal desde 2013 hasta 2018. También hubo una categorización a través del análisis de contenido (BARDIN, 2011) en la cual se diseccionaron los trabajos para percibir aproximaciones de metodologías activas con interdisciplinariedad. Como resultados, podemos destacar que las metodologías activas contribuyen a crear condiciones que mejoran el desarrollo de la interdisciplinariedad, ya que proporcionan a los discentes situaciones que permiten la experiencia y la búsqueda de la construcción del conocimiento a través del proceso de diálogo, estructurado intelectualmente, entre ellos, y entre las áreas de conocimiento. Sin embargo, a pesar de su innegable importancia, las prácticas interdisciplinares son todavía muy incipientes y no ocurren, efectivamente, como acción pedagógica y esta realidad debe transformarse, por lo que es necesário llevar a cabo investigaciones científicas que se centren en la práctica de la interdisciplinariedad.

Descriptores: Metodologías activas. Interdisciplinariedad. Educación básica.

\section{INTRODUÇÃO}

O sistema educacional determina que cada disciplina deve ser marcada por uma base comum que visa justificar e the dar a devida importância no contexto escolar. No entanto, os tempos atuais exigem reformulações nessas bases, de forma que a prática docente seja inovadora e que o processo de ensino e de aprendizagem não seja somente estabelecido de forma tradicional, centrada no isolamento dos conhecimentos de cada disciplina, ou seja, de forma "bancária" (ALVARENGA et al., 2015).

Diante da preocupação com essa educação bancária e com avanços nas discussões no cenário educacional, revelou-se a limitação da disciplinarização do conhecimento (os fenômenos complexos do mundo natural, social e cultural são divididos em ramos chamados de disciplinas, sendo cada disciplina responsável por uma parcela do conhecimento naquele ramo e os fenômenos dessa parcela são analisados sem levar em conta suas interações com as demais parcelas de conhecimento do mesmo campo) e passa-se, então, a pensar em interdisciplinaridade (ALVARENGA et al., 2015).
É necessário compreender que a ideia de tratar os conhecimentos das disciplinas das diversas áreas do conhecimento de forma integrada não é novidade, pois os gregos já buscavam trabalhar com essa abordagem. Entretanto, o movimento da interdisciplinaridade no ensino dá início a sua trajetória na década de 60, principalmente na Europa, tendo como foco a França e a Itália, onde ocorreram reivindicações estudantis para que houvesse a melhoria da qualidade do ensino e para que esse fosse o mais próximo da realidade social, política e econômica dos discentes (FAZENDA, 1998).

Como resultados dessas reivindicações, muitos estudos foram realizados e muitas obras publicadas. Como exemplo, pode-se citar as contribuições das obras de Fazenda (1998; 2013), Santos (2007), de Philippi Jr. (2015) e de outras publicações na área de interdisciplinaridade no Brasil. No entanto, os estudiosos que praticam, teorizam e tentam definir interdisciplinaridade ainda não conseguem proporcionar uma única definição, devido às suas múltiplas dimensões epistemológicas e das similitudes e diferenças apresentadas pelos estudiosos. 
Trazendo para o contexto educacional brasileiro atual e principalmente no Ensino Médio, ainda que a conceituação da interdisciplinaridade não seja clara, percebe-se que a gestão escolar e as políticas públicas educacionais sugerem que a prática docente deve ser guiada por essa abordagem. Como exemplos, os Parâmetros Curriculares Nacionais (PCN) para o Ensino Médio de 2000 (BRASIL, 2000) e as Diretrizes Curriculares Nacionais para o Ensino Médio (DCNEM) de 2012 (BRASIL, 2012).

Diante do exposto, o presente artigo tem como objetivo refletir acerca das contribuições e implicações das metodologias ativas no desenvolvimento da interdisciplinaridade no processo de ensino e aprendizagem. Para essa reflexão foi realizada uma pesquisa documental de 18 produções científicas de quatro periódicos disponibilizados no Portal de Periódicos da Coordenação e Aperfeiçoamento de Pessoal de Nível Superior (CAPES) com Qualis A1, A2, B1 e B2, e também dos anais do Simpósio Nacional de Ensino de Ciência e Tecnologia (SINECT), tendo como recorte temporal o período de 2013 a 2018. Para análise dos trabalhos, houve também uma categorização por meio da análise de conteúdo (BARDIN, 2011) para perceber aproximações das metodologias ativas com a interdisciplinaridade.

A escolha e justificativa desses trabalhos se dá mediante ter obtido um corpus de análise em um levantamento realizado para a construção de outra pesquisa e pela potencialidade desse corpus acerca das metodologias ativas e de pensar a interdisciplinaridade no ensino médio.

\section{TECENDO SABERES ACERCA DA INTERDISCIPLINARIDADE}

Pensar no cotidiano da escola pública, torna possível a formação em nossas mentes de uma gama de situações tidas como problemáticas ou impactantes. Destas, podemos destacar o trabalho com a interdisciplinaridade (ALVARENGA et al., 2015).

Percebemos que essas situações estão relacionadas com o fato da interdisciplinaridade ser entendida como uma abordagem filosófica, que apresenta significados tanto de caráter científicos, culturais e também sociais, que visam no contexto atual, "socorrer" o processo de ensino e aprendizagem fornecendo-lhe uma nova face, pois visa proporcionar uma transformação nas práticas pedagógicas (ALVARENGA et al., 2015).

Com o intuito de abordar a gênese da interdisciplinaridade, Alvarenga et al. (2015, p. 58) aduz que

[...] a interdisciplinaridade emerge nos anos 1960 como precursora não somente na crítica, mas sobretudo na busca de respostas aos limites do conhecimento disciplinar que sustenta o paradigma da ciência moderna, considerado por pensadores da educação e da ciência como simplificador, fragmentador e redutor do conhecimento. Em função de sua proposta, passa a configurar-se como um modo inovador na produção do conhecimento que não nega o disciplinar, mas o complementa e amplia apresentando-se, nesse caso, como alternativo -, quando busca focar a questão da complexidade e dos desafios à religação dos saberes.

Sendo utilizado desde os anos 60 a partir de um movimento revolucionário de universitários, o termo interdisciplinaridade apresenta algumas variâncias que são os termos: "transdisciplinaridade", "multidisciplinaridade" dentre outros que vão se derivando quando as discussões vão se aprofundando. No entanto, é necessário entender que o termo interdisciplinaridade, mesmo com suas variâncias não apresenta uma única definição, mas é compreendido, independente disto, como uma possibilidade real de quebrar com a rigidez dos "compartimentos" em que 
se encontram separadas as disciplinas do currículo das escolas (ALVARENGA et al., 2015).

Mesmo não apresentando uma única definição, Alvarenga et al. (2015, p. 59) salienta que

[...] a interdisciplinaridade passa a propor a conjunção como proposta de (re)ligação dos saberes. Nesse sentido, começa a negar o pressuposto básico do conhecimento disciplinar de que existe, segundo Khun (1978), um 'vazio' de realidade entre as fronteiras disciplinares.

Sendo assim, é preciso identificar alguns fatos que sustentam e apontam para a importância da interdisciplinaridade na atualidade e há que considerar que, embora a ideia de interdisciplinaridade não seja nova,

Nova é a sua proposta dada as suas relações estreitas com o modo de produzir conhecimento na ciência moderna ou clássica. Assim, ao propor-se a operar nas fronteiras disciplinares e na religação de saberes, a interdisciplinaridade aproxima-se dos desafios colocados a essa ciência, notadamente o de dar conta dos fenômenos complexos (KLEIN,1996 citado por ALVARENGA et al. 2015, p. 61).

Sem ter a pretensão de uma longa discussão sobre o conceito do termo, a interdisciplinaridade pode ser entendida aqui como uma perspectiva de trabalho pedagógico que visa promover o diálogo constante de saberes, no qual essa conversa entre as diversas áreas do conhecimento e seus respectivos conteúdos, se dariam como o entrelaçamento entre os diversos fios que tecem o currículo escolar, de modo que possa fortalecer, qualificar e contextualizar o processo de aprendizagem dos discentes em seus respectivos níveis de ensino (FAZENDA, 1998).

Em relação aos níveis de ensino, é perceptível que, apesar de presente nos documentos oficiais norteadores da educação básica, a interdisciplinaridade é ainda considerada como algo distante da realidade do cotidiano escolar, fazendo refletir se, de fato, será efetivamente trabalhada enquanto proposta pedagógica (FAZENDA, 1998).

Mediante essa consideração e realizando uma busca para contextualizar este aspecto, observase que, nos Parâmetros Curriculares Nacionais (PCN) para o Ensino Médio, o trabalho interdisciplinar consta como uma proposta de acabar com o ensino fragmentado, compartimentalizado e descontextualizado, sendo indicado o

[...] desenvolvimento do currículo de forma orgânica, superando a organização por disciplinas estanques e revigorando a integração e articulação dos conhecimentos, num processo permanente de interdisciplinaridade (BRASIL, 2000, p. 17).

Partindo-se da análise das Diretrizes Curriculares Nacionais para o Ensino Médio (DCNEM) - Resolução nº. 2, de 30 de janeiro 2012, percebe-se que o currículo do Ensino Médio está organizado em áreas do conhecimento, sendo estabelecidas no Art. $8^{\circ}$, a saber: "I - Linguagens; II Matemática; III - Ciências da Natureza; IV - Ciências Humanas" (BRASIL, 2012). As referidas áreas são consideradas, também, no Exame Nacional do Ensino Médio (ENEM).

Outro destaque a ser feito nas Diretrizes Curriculares Nacionais para o Ensino Médio (DCNEM) é o fato de a interdisciplinaridade ser um dos princípios pedagógicos que deve embasar o Ensino Médio; ficando claro em seu Art. $5^{\circ}$, que "o Ensino Médio em todas as suas formas de oferta e organização, baseia-se em: [...] VI - integração de conhecimentos gerais e, quando for o caso, técnicoprofissionais realizada na perspectiva da interdisciplinaridade e da contextualização" (BRASIL, 2012).

Apesar de se apresentarem um pouco modestas as considerações nos documentos oficiais da 
educação básica acerca da interdisciplinaridade, é notório que nos documentos referentes ao Ensino Médio tais propostas são mais recorrentes. No entanto, na maioria das instituições de ensino esse trabalho interdisciplinar não acontece efetivamente e quando ocorre não é significativo, ou seja, o termo é mencionado mais que praticado; é escrito mais que utilizado em ação pedagógica promotora das aprendizagens necessárias ao ser humano de hoje. Está previsto e suposto nos documentos legais da educação básica, mas não no cotidiano da escola, no fazer pedagógico, e assim percebemos que é retórica e não prática (ALVARENGA et al., 2015; FAZENDA, 1998).

\section{METODOLOGIAS ATIVAS: EXPERIÊNCIAS NO ENSINO}

Pensar nos processos de ensino e de aprendizagem exige considerar todas as variáveis que estão no seu entorno, para que assim se possa, compreendendo os agentes, as metodologias e tudo que concorre para construção do conhecimento de uma determinada área, avaliar e discutir como estão sendo efetivados esses processos. Com essa preocupação em abordar essas variáveis, Coelho (2017, p. 178) enfatiza que

Ensinar é um processo por meio do qual o professor (profissional que ensina) executa práticas que tornam possível a comunicação eficaz entre o objeto da aprendizagem (o que se quer aprender) e o sujeito aprendiz. Para maior efetividade desses processos, o professor deve avaliar a melhor forma de fazer a mediação entre o cérebro do seu aluno e os desafios oriundos da área em estudo. É, pois, um processo que deve se basear na capacidade plástica do cérebro humano, buscando a construção e o reforço de sinapses visando à adequada aquisição, memorização, tratamento e processamento dos conhecimentos aos quais o aluno foi exposto.
Dessa forma, compreende-se que aprender é um ato voluntário do aprendiz. Pois, quando se aprende algo o cérebro deve reagir aos estímulos advindos do ambiente e reconfigurar-se ativando sinapses, tornando-as mais intensas, levando à configuração de circuitos mais eficazes para o processamento da informação recebida (COELHO, 2017).

Ainda Coelho (2017, p. 178-179) afirma que "[...] atenção e motivação do aprendiz exige esforço, responsabilidade, escolha e disciplina. Sem esses elementos, qualquer método, [...], se torna vazio. Neste ponto, exige-se que o professor atue, sobretudo, como um motivador".

Diante do exposto, compreende-se que o método selecionado para conduzir o processo de ensino e aprendizagem é fundamental para o processo. É nesse ponto que as metodologias ativas surgem como "pontos de partida para avançar para processos mais avançados de reflexão, de integração cognitiva, de generalização, de reelaboração de novas práticas" (MORAN, 2015, p. 18).

Em relação a compreensão das metodologias ativas, Coelho (2017, p. 179) faz a seguinte abordagem.

Os métodos ativos surgem como uma proposta de atitudes e procedimentos que devem ser levados a cabo com o intuito de que alunos e professores possam ter o máximo controle sobre seus processos de ensino-aprendizagem e um melhor aproveitamento destes. A prática baseada em métodos ativos tem em seus objetivos conduzir o aluno no caminho de construção do seu próprio conhecimento, tornando-o, por consequência, sujeito autônomo, crítico e reflexivo.

Entendemos assim que as metodologias ativas têm como ponto principal tornar o estudante o protagonista da construção do seu conhecimento, 
aprendendo no seu próprio ritmo e também com os outros.

Percebemos que a nova ênfase dada ao processo de aprender a partir da ação das metodologias ativas, proporciona uma nova reflexão nos papeis que os estudantes e professores desenvolvem no processo de ensino e de aprendizagem, pois o estudante é direcionado para o centro do processo educativo, aumentando sua responsabilidade em relação à sua formação. Já o professor fica encarregado de apresentar o mundo e, ao mesmo tempo, deixá-lo caminhar sozinho (MORAN, 2015).

Entretanto, ainda se percebe a existência de muitos equívocos quanto à compreensão e eficácia da aplicação das metodologias ativas, havendo muitas vezes divergências entre o que as práticas pedagógicas descrevem e a forma como elas realmente acontecem, fazendo-se, pois, necessárias, mais discussões e produções científicas acerca da importância das metodologias ativas para a construção do conhecimento autônomo do aluno no processo de ensino e de aprendizagem na educação básica e, em específico, no Ensino Médio (COELHO, 2018; MORAN, 2015).

\section{METODOLOGIA}

A pesquisa se ampara na abordagem qualitativa. Segundo Callado e Lucio (2013, p. 376) pesquisas desse tipo têm o intuito de "compreender e aprofundar os fenômenos, que são explorados a partir da perspectiva dos participantes em um ambiente natural e em relação ao contexto". Para esse trabalho, essa abordagem tem como intuito compreender, por meio da análise das produções científicas, quais as contribuições e implicações das metodologias ativas de ensino e aprendizagem para o desenvolvimento da interdisciplinaridade.

A coleta de dados se deu mediante um levantamento prévio realizado para outra pesquisa ${ }^{1}$, na qual se estrutura o referido corpus de análise que é composto de 18 (dezoito) trabalhos de periódicos disponibilizados no Portal de Periódicos da Coordenação e Aperfeiçoamento de Pessoal de Nível Superior (CAPES) e também dos anais do VI Simpósio Nacional de Ensino de Ciência - SINETC.

Para compor o corpus de análise foram selecionados os trabalhos mediante algumas etapas: (1) escolha das palavras-chave para busca nas fontes (Metodologias Ativas, Ensino Médio, Ensino de Ciências Naturais); (2) localização das fontes online de pesquisas (CAPES, SINECT); (3) coleta das produções científicas; (4) leitura dos títulos e resumos, com elaboração de sínteses dos resultados. Vale salientar que é importante dar atenção aos títulos, pois os mesmos fazem menção, como aborda Ferreira (2002, p. 261) "a informação principal do trabalho ou indicam elementos que caracterizam o seu conteúdo"; e (5) análise e elaboração das considerações preliminares.

Dentre os periódicos, analisamos trabalhos da Revista Brasileira de Ensino de Física (RBEF); Caderno Brasileiro de Ensino de Física (CBEF); Revista Eletrônica Científica Ensino Interdisciplinar (RECEI) e; Revista Física na Escola, os quais são, atualmente, avaliados com Qualis A1, A2, B1 e B2 (classificação 2013-2016 da CAPES), respectivamente. $\mathrm{E}$ tendo como recorte temporal o período de 2013 a 2018.

1 Trata-se de um "Estado da Arte" realizado para a disciplina de Pesquisa em Ensino do Programa de PósGraduação em Ensino - POSENSINO (associação entre IFRN, UERN e UFERSA). 
Como método de análise qualitativa, foi realizada uma Análise de Conteúdo. Segundo Bardin (2011, p. 42) esse método pode ser entendido como

"[...] uma técnica de investigação que através de uma descrição objetiva, sistemática e quantitativa do conteúdo manifesto das comunicações tem por finalidade a interpretação destas mesmas comunicações.".

A análise do conteúdo de uma comunicação (não necessariamente um texto) por meio desse método consiste, basicamente, em três fases distintas cronologicamente. A primeira dessas fases é a préanálise que:

"corresponde a um período de intuições, mas que tem por objetivo tornar operacionais e sistematizar as ideias iniciais, de maneira a conduzir a um esquema preciso do desenvolvimento das operações sucessivas" (BARDIN, 2011, p. 125).

É nesta etapa que se estabelece quais os documentos que serão analisados, quais as hipóteses para a pesquisa e a formulação dos indicadores que fundamentam a interpretação final.

Em seguida, procede-se com a fase de exploração do material que "[...] não é mais do que a aplicação sistemática das decisões tomadas na préanálise" (BARDIN, 2011, p. 131).

Na última etapa, a de tratamento,

"Os resultados brutos são tratados de maneira a serem significativos ("falantes") e válidos. Operações estatísticas simples (percentagem), ou mais complexas (análise fatorial), permitem estabelecer quadros de resultados, diagramas, figuras e modelos, os quais condensam e põem em relevo as informações fornecidas pela análise. (BARDIN, 2011, p. 131).

Definimos a priori categorias de uma metodologia de ensino que caracterizassem uma proposta interdisciplinar, quais sejam: "contextualização", "ser baseado nas experiências do aluno", "unidade problematizadora", "atitude no relacionamento com o conhecimento", "projetos de interação das disciplinas", "interação dos pontos de vistas ou os discursos das várias disciplinas e "revisão de formas de aprender a realidade". A definição dessas categorias baseou-se nos trabalhos de Fazenda (2008), Castro e Melo (2015) e Japiassu (1994).

A análise consistiu em buscar, dentre as publicações analisadas, falas dos autores, que indicassem características, aspectos, semelhanças que aproximassem suas práticas de propostas interdisciplinares aqui representadas pelas categorias acima elencadas.

\section{ANÁLISE E DISCUSSÃO DOS RESULTADOS}

Após a coleta, foram tabulados os dados e posteriormente elaborados quadros e gráficos no Excel para uma melhor exposição e discussão dos dados. A Tabela 1 apresenta o corpus de análise, onde apresenta-se os títulos dos trabalhos, ano de publicação, fonte e os seus respectivos autores.

Tabela 1 - Corpus de Análise

\begin{tabular}{ccccc}
\hline $\mathbf{N}^{\mathbf{2}}$ & TRABALHOS & $\begin{array}{c}\text { ANO DE } \\
\text { PUBLICAÇÃO }\end{array}$ & FONTE & AUTORES \\
\hline $\mathbf{0 1}$ & $\begin{array}{c}\text { Gamificação aplicada ao plano } \\
\text { de aula: elementos para } \\
\text { potencializar o ensino }\end{array}$ & 2017 & RECEI & $\begin{array}{c}\text { FORTUNATO, I. } \\
\text { TEICHNER, O. T. }\end{array}$ \\
\hline $\mathbf{0 2}$ & $\begin{array}{c}\text { Uma comparação entre Team- } \\
\text { Based Learning e Peer- } \\
\text { Instruction em turmas de Física } \\
\text { do Ensino Médio }\end{array}$ & 2018 & RECEI & COELHO, M. N. \\
\hline $\mathbf{0 3}$ & A utilização do aplicativo & 2018 & RECEI & SILVA, D. O. \\
\hline
\end{tabular}




\begin{tabular}{|c|c|c|c|c|}
\hline & $\begin{array}{l}\text { Plickers como ferramenta na } \\
\text { implementação da metodologia } \\
\text { Pee-Instruction }\end{array}$ & & & $\begin{array}{l}\text { SALES, G. L. } \\
\text { CASTRO, J. B. }\end{array}$ \\
\hline 04 & $\begin{array}{c}\text { Instrução pelos Colegas e Ensino } \\
\text { sob Medida: Uma proposta para } \\
\text { o engajamento dos alunos no } \\
\text { processo de ensino } \\
\text { aprendizagem de Física }\end{array}$ & 2013 & CBEF & $\begin{array}{l}\text { ARAUJO, I. S. } \\
\text { MAZUR, E. }\end{array}$ \\
\hline 05 & $\begin{array}{l}\text { Relato de experiência com os } \\
\text { métodos Ensino sob Medida } \\
\text { (Just -in-Time Teaching) e } \\
\text { Instrução pelos Colegas (Peer- } \\
\text { Instruction) para o Ensino de } \\
\text { Tópicos de Eletromagnetismo no } \\
\text { nível médio }\end{array}$ & 2015 & CBEF & $\begin{array}{l}\text { OLIVEIRA, V. } \\
\text { VEIT, E. A. } \\
\text { ARAUJO, I. S. }\end{array}$ \\
\hline 06 & $\begin{array}{c}\text { Aprendizagem Baseada em } \\
\text { Equipes (Team-Based Learning): } \\
\text { um método ativo para o Ensino } \\
\text { de Física } \\
\end{array}$ & 2016 & CBEF & $\begin{array}{l}\text { OLIVEIRA, T. E. } \\
\text { ARAUJO, I. S. } \\
\text { VEIT, E. A. }\end{array}$ \\
\hline 07 & $\begin{array}{l}\text { Sala de aula invertida (Flipped } \\
\text { Classroom): Inovando as aulas } \\
\text { de Física }\end{array}$ & 2016 & $\begin{array}{c}\text { Revista } \\
\text { Física na } \\
\text { Escola } \\
\end{array}$ & $\begin{array}{l}\text { OLIVEIRA, T. E. } \\
\text { ARAUJO, I. S. } \\
\text { VEIT, E. A. } \\
\end{array}$ \\
\hline 08 & $\begin{array}{c}\text { Abordando os fenômenos de } \\
\text { difração e interferência de ondas } \\
\text { com o método da instrução pelos } \\
\text { colegas (Peer-Instruction) }\end{array}$ & 2015 & $\begin{array}{c}\text { Revista } \\
\text { Física na } \\
\text { Escola }\end{array}$ & $\begin{array}{l}\text { JARDIM, W. T. } \\
\text { SILVA, M. A. M. } \\
\text { BARROS, M. V. }\end{array}$ \\
\hline 09 & $\begin{array}{c}\text { Uma metodologia de } \\
\text { aprendizagem ativa para o ensino } \\
\text { de mecânica em educação de } \\
\text { jovens e adultos }\end{array}$ & 2015 & RBEF & $\begin{array}{l}\text { SANTOS, R. J. } \\
\text { SASAKI, D. G. G. }\end{array}$ \\
\hline 10 & $\begin{array}{l}\text { Uma associação do método } \\
\text { Peer-Instruction com circuitos } \\
\text { elétricos em contextos de } \\
\text { aprendizagem ativa }\end{array}$ & 2017 & RBEF & $\begin{array}{l}\text { ARAUJO, A. V. R. } \\
\text { SILVA, E. S. } \\
\text { JESUS, V. L. B. } \\
\text { OLIVEIRA, A. L. }\end{array}$ \\
\hline 11 & $\begin{array}{c}\text { Avaliação de uma metodologia } \\
\text { de aprendizagem ativa em óptica } \\
\text { geométrica através da } \\
\text { investigação das reações dos } \\
\text { alunos }\end{array}$ & 2017 & RBEF & $\begin{array}{l}\text { SASAKI, D. G. G. } \\
\text { JESUS, V. L. B. }\end{array}$ \\
\hline 12 & $\begin{array}{l}\text { Uma revisão da literatura acerca } \\
\text { da implementação metodologia } \\
\text { interativa de ensino Peer- } \\
\text { Instruction (1991 a 2015) }\end{array}$ & 2017 & RBEF & $\begin{array}{l}\text { MULLER, M. G. } \\
\text { ARAUJO, I, S. } \\
\text { VEIT, E. A. } \\
\text { SCHELL, J. }\end{array}$ \\
\hline 13 & $\begin{array}{l}\text { A problem regarding buoyancy } \\
\text { of simple figures suitable for } \\
\text { Problem-Based Learning }\end{array}$ & 2017 & RBEF & $\begin{array}{l}\text { SANTANDER, J. } \\
\text { L. G. } \\
\end{array}$ \\
\hline 14 & $\begin{array}{c}\text { Implementação de um aplicativo } \\
\text { para smartphones como sistema } \\
\text { de votação em aulas de Física } \\
\text { com Peer-Instruction } \\
\end{array}$ & 2017 & RBEF & $\begin{array}{l}\text { KIELT, E. D. } \\
\text { SILVA, S. C. R. } \\
\text { MIQUELIN, A. F. }\end{array}$ \\
\hline 15 & $\begin{array}{l}\text { Peer-Instruction to address } \\
\text { alternative conceptions in } \\
\text { Einstein's special relativity }\end{array}$ & 2017 & RBEF & $\begin{array}{c}\text { ALVAREZ- } \\
\text { ALVARADO, M. } \\
\text { S. } \\
\text { MORA, C. } \\
\text { CEVALLOS- } \\
\text { REYES, C. B. } \\
\end{array}$ \\
\hline 16 & $\begin{array}{c}\text { Juntos num só ritmo: } \\
\text { modificando a dinâmica das } \\
\text { aulas de Física com uso } \\
\text { articulado do Peer-Instruction e } \\
\text { Just In Time }\end{array}$ & 2014 & SINECT & $\begin{array}{l}\text { SILVA, J. J. } \\
\text { FIGUEIREDO, N. } \\
\text { RODRIGUES, P. } \\
\text { A. A. }\end{array}$ \\
\hline
\end{tabular}




\begin{tabular}{|c|c|c|c|c|}
\hline 17 & $\begin{array}{c}\text { Unidades de Aprendizagem } \\
\text { Ativa para Física - Motivação } \\
\text { Acadêmica } \\
\end{array}$ & 2018 & SINECT & $\begin{array}{l}\text { COELHO, M. N. } \\
\text { VIEIRA, S. M. }\end{array}$ \\
\hline 18 & $\begin{array}{l}\text { Uma proposta de UEPS } \\
\text { utilizando o ciclismo para o } \\
\text { ensino de tópicos de Mecânica }\end{array}$ & 2018 & SINECT & $\begin{array}{l}\text { BARUMBY, J. C. } \\
\text { HILGER, T. R. } \\
\text { CAMRGO, S. }\end{array}$ \\
\hline
\end{tabular}

Fonte: Dados da Pesquisa (2019)

Importante destacar o relativamente elevado quantitativo de trabalhos publicados na RBEF no período considerado (sete). Este periódico destaca-se, a nível nacional e internacional, como uma publicação de enorme relevância na área de Ensino. Com base no Tabela 1 acima e para que haja uma visualização do quantitativo de trabalhos por ano, o Gráfico 1 apresenta essa distribuição entre 2013 e 2018.

Gráfico 1:Quantitativo de Trabalhos (2013 - 2018)

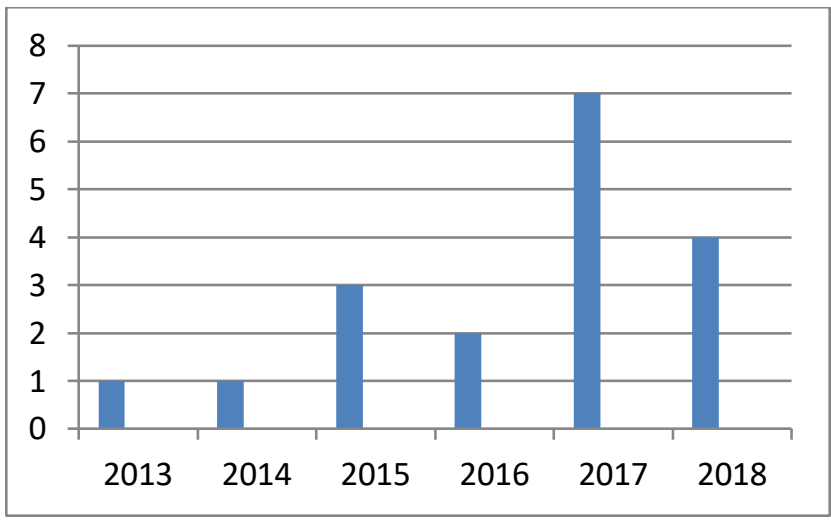

Fonte: Dados da Pesquisa (2019)

Percebe-se segundo o gráfico que houve um expressivo número de trabalhos ano de 2017 38,88 \% que tratam de metodologias ativas. Já em 2013 e 2014 houve 5,55\% (em cada ano). Em 2015 teve 16,66\%, $201611,11 \%$ e no ano de 2018 teve 22, $22 \%$. Esses dados sugerem uma tendência crescente no uso das metodologias ativas em salas de aula a partir de 2013. Todos os trabalhos analisados tratam de aplicações de metodologias ativas em ambiente formal de ensino. Eles também deixam explícito o quanto é escassa a preocupação com pesquisas que discutam pressupostos teóricos e/ou filosóficos dessas metodologias.

É nesse sentido que este trabalho se apresenta de muita relevância, pois, ao discutir características interdisciplinares das metodologias ativas, pretende ser uma semente na direção de novos estudos com esse foco.

A análise das publicações revelou falas dos autores (pesquisadores) que guardavam correspondências com as categorias de análise definidas na seção de Metodologia (contextualização, ser baseado nas experiências do aluno, unidade problematizadora, atitude no relacionamento com o conhecimento, projetos de interação das disciplinas, interação dos pontos de vistas ou os discursos das várias disciplinas e revisão de formas de aprender a realidade).

A seguir, na Tabela 2, apresentamos alguns trechos das publicações estudadas, selecionados a partir da análise, como representativos de cada uma das categorias já mencionadas.

Tabela 2: Análise das Categorias

\begin{tabular}{ccc}
\hline CATEGORIAS & TRABALHOS & FALAS DOS TRABALHOS \\
\hline & $\begin{array}{c}\text { Abordando os fenômenos de } \\
\text { difração e interferência de } \\
\text { ondas com o método da } \\
\text { instrução pelos colegas } \\
\text { (Peer-Instruction) }\end{array}$ & $\begin{array}{c}\text { "[...] constituiu uma proposta que pode } \\
\text { ser reproduzida em outros contextos de } \\
\text { sala de aula". }\end{array}$ \\
\cline { 2 - 3 } & Juntos num só ritmo: & "A possibilidade do aluno ter contato \\
\hline
\end{tabular}


SER BASEADO NAS ALUNO

\section{ATITUDE NO \\ RELACIONAMENTO COM O CONHECIMENTO}
modificando a dinâmica das aulas de Física com uso articulando do PeerInstruction e Just In Time
Gamificação aplicada ao plano de aula: elementos para potencializar o ensino com o conteúdo antes das aulas é um fator que auxilia na articulação mais adequada do conteúdo com o contexto do aluno, além de instigá-los na busca de informações que poderão vir a ser estruturadas em sala de aula.

"A abordagem aqui apresentada espera privilegiar uma visão do aluno sobre o seu passado e o seu futuro de aprendizado, identificando o quanto progrediu e pode progredir, indo muito além da "diversão" dos jogos e da preparação da escola"

Uma comparação entre

Team-Based Learning e

Peer-Instruction em turmas de Física do Ensino Médio

A utilização do aplicativo
Plickers como ferramenta na
implementação da
metodologia Peer-Instruction

Gamificação aplicada ao plano de aula: elementos para potencializar o ensino “[...] é essencial para o bom desempenho da turma, que os alunos trabalhem em equipe".

"Notou-se que no decorrer das discussões os estudantes defendiam seus pontos de vista, mas se mostravam receptivos às idéias dos colegas, utilizando argumentos e promovendo um debate saudável". "[...] o foco de nosso plano de aula gameficado é reforçar a sensação de progresso com o uso dos elementos de jogos, para que os alunos possam estudar, voluntariamente".

“[...] Seus pontos fortes estão em

Instrução pelos Colegas e Ensino sob Medida: Uma proposta para o engajamento dos alunos no processo de ensino aprendizagem de Física considerar o conhecimento prévio do aluno, favorecer interações sociais voltadas para a construção do conhecimento e estabelecer as bases para o desenvolvimento de habilidades metacognitivas, começando pela criação de hábitos de estudos por parte dos alunos".

"[...] tem sua importância no fato de que aponta caminhos para a elaboração de Unidades de Aprendizagem Ativas capazes de promover, além de uma aprendizagem mais significativa, um nível mais autônomo de motivação". "É esperado que com esta sequência didática seja possível mensurar as relações dos alunos com os tópicos de mecânica apresentados no currículo".

\begin{tabular}{|c|c|}
\hline $\begin{array}{c}\text { Uma proposta de UEPS } \\
\text { utilizando o ciclismo para o } \\
\text { ensino de tópicos de } \\
\text { Mecânica }\end{array}$ & $\begin{array}{l}\text { "É esperado que com esta sequência } \\
\text { didática seja possível mensurar as } \\
\text { relaçõos dos alunos com os tópicos de } \\
\text { mecânica apresentados no currículo". }\end{array}$ \\
\hline $\begin{array}{c}\text { Uma associação do método } \\
\text { Peer-Instruction com } \\
\text { circuitos elétricos em } \\
\text { contextos de aprendizagem } \\
\text { ativa } \\
\end{array}$ & $\begin{array}{l}\text { “[...] os alunos fossem capazes de } \\
\text { analisar, de forma autônoma, o } \\
\text { comportamento dos circuitos } \\
\text { apresentados e de outros análogos". }\end{array}$ \\
\hline $\begin{array}{c}\text { Relato de experiência com os } \\
\text { métodos Ensino sob Medida } \\
\text { (Just-in-Time Teaching) e } \\
\text { Instrução pelos Colegas } \\
\text { (Peer-Instruction) para o } \\
\text { Ensino de Tópicos de } \\
\text { Eletromagnetismo no nível } \\
\text { médio. }\end{array}$ & $\begin{array}{c}\text { "Pensar alternativas para saber fazer } \\
\text { com que os alunos se envolvam no } \\
\text { processo de ensino aprendizagem e } \\
\text { saber criar um ambiente propício no } \\
\text { qual os estudantes possam alcançar } \\
\text { uma aprendizagem significativa dos } \\
\text { conteúdos". }\end{array}$ \\
\hline
\end{tabular}

Unidades de Aprendizagem Ativa para Física Motivação Acadêmica 


\begin{tabular}{|c|c|c|}
\hline & $\begin{array}{l}\text { Peer-Instruction to address } \\
\text { alternative conceptions in } \\
\text { Einstein's special relativity }\end{array}$ & $\begin{array}{l}\text { "[...] traz uma aprendizagem de alto } \\
\text { ganho, que abre um caminho para a } \\
\text { inclusão do tema da relatividade } \\
\text { especial de Einstein em currículos } \\
\text { escolares". }\end{array}$ \\
\hline \multirow{3}{*}{$\begin{array}{c}\text { UNIDADE } \\
\text { PROBLEMATIZADORA }\end{array}$} & $\begin{array}{l}\text { Uma comparação entre } \\
\text { Team-Based Learning e } \\
\text { Peer-Instruction em turmas } \\
\text { de Física do Ensino Médio }\end{array}$ & $\begin{array}{c}\text { "[...] sendo essencial para a eficiência } \\
\text { do método que a etapa de discussão } \\
\text { dos problemas seja encarada com } \\
\text { empenho pelos alunos". }\end{array}$ \\
\hline & $\begin{array}{l}\text { Sala de aula invertida } \\
\text { (Flipped Classroom): } \\
\text { inovando as aulas de Física }\end{array}$ & $\begin{array}{l}\text { "O professor revisa os problemas de } \\
\text { casa. Em seguida, os alunos são } \\
\text { organizados em grupos e recebem } \\
\text { novos e mais complexos problemas } \\
\text { para resolverem". }\end{array}$ \\
\hline & $\begin{array}{c}\text { A problem regarding } \\
\text { buoyancy of simple figures } \\
\text { suitable for Problem-Based } \\
\text { Learning }\end{array}$ & $\begin{array}{c}\text { "Para resolver o problema, duas } \\
\text { afirmações precisam ser } \\
\text { consideradas". }\end{array}$ \\
\hline \multirow{2}{*}{$\begin{array}{l}\text { PROJETOS DE } \\
\text { INTERAÇÃO DAS } \\
\text { DISCIPLINAS }\end{array}$} & $\begin{array}{l}\text { Implementação de um } \\
\text { aplicativo para smartphones } \\
\text { como sistema de votação em } \\
\text { aulas de Física com Peer- } \\
\text { Instruction }\end{array}$ & $\begin{array}{c}\text { “[...] têm potencial para utilização em } \\
\text { sala de aula e além dela. A } \\
\text { possibilidade de estudos fora da sala } \\
\text { de aula é um recurso que fortalece a } \\
\text { aprendizagem, a autonomia e conduz a } \\
\text { ter hábitos de estudos. Também é } \\
\text { possível manter contato com colegas e } \\
\text { executar trabalhos colaborativos". }\end{array}$ \\
\hline & $\begin{array}{l}\text { Uma revisão da literatura } \\
\text { acerca da implementação } \\
\text { metodologia interativa de } \\
\text { ensino Peer-Instruction } \\
\text { (1991 a 2015) }\end{array}$ & $\begin{array}{c}\text { "O sucesso obtido pelas primeiras } \\
\text { adoções dessa metodologia, bem como } \\
\text { a aspiração dos professores em } \\
\text { modificarem suas práticas docentes, } \\
\text { motivou muitos pesquisadores a } \\
\text { aplicarem o Peer-Instruction em } \\
\text { diversas disciplinas e contextos } \\
\text { educacionais". }\end{array}$ \\
\hline $\begin{array}{c}\text { INTERAÇÃO DOS } \\
\text { PRONTOS DE VISTAS OU } \\
\text { OS DISCURSOS DAS } \\
\text { VÁRIAS DISCIPLINAS }\end{array}$ & $\begin{array}{c}\text { Avaliação de uma } \\
\text { metodologia de } \\
\text { aprendizagem ativa em óptica } \\
\text { geométrica através da } \\
\text { investigação das reações dos } \\
\text { alunos } \\
\end{array}$ & $\begin{array}{c}\text { "Esse conhecimento serviria para } \\
\text { aperfeiçoar as estratégias de ensino } \\
\text { que fazem uso do conflito cognitivo } \\
\text { em sala de aula'. }\end{array}$ \\
\hline \multirow{4}{*}{$\begin{array}{l}\text { REVISÃO DE FORMAS } \\
\text { DE APRENDER A } \\
\text { REALIDADE }\end{array}$} & $\begin{array}{c}\text { A utilização do aplicativo } \\
\text { Plickers como ferramenta na } \\
\text { implementação da } \\
\text { metodologia Peer-Instruction }\end{array}$ & $\begin{array}{c}\text { “[...] Se o professor possuir um } \\
\text { computador que possa utilizar em sala } \\
\text { de aula e acesso à internet o Plickers } \\
\text { torna a atividade ainda mais interativa, } \\
\text { permitindo o feedback imediato às } \\
\text { respostas dos alunos". }\end{array}$ \\
\hline & $\begin{array}{l}\text { Abordando os fenômenos de } \\
\text { difração e interferência de } \\
\text { ondas com o método da } \\
\text { instrução pelos colegas } \\
\text { (Peer-Instruction) }\end{array}$ & $\begin{array}{l}\text { "[...] instigar a criação de novos } \\
\text { trabalhos, que podem ser adaptados e } \\
\text { implementados sobre diferentes } \\
\text { conteúdos e em distintas realidades". }\end{array}$ \\
\hline & $\begin{array}{c}\text { Sala de aula invertida } \\
\text { (Flipped Classroom): } \\
\text { inovando as aulas de Física }\end{array}$ & $\begin{array}{l}\text { "A partir do contato prévio com o } \\
\text { conteúdo, ele tem tempo para pensar } \\
\text { sobre o que está estudando". }\end{array}$ \\
\hline & $\begin{array}{l}\text { Aprendizagem Baseada em } \\
\text { Equipes (Team-Based } \\
\text { Learning): um método ativo } \\
\text { para o Ensino de Física }\end{array}$ & $\begin{array}{l}\text { “As estratégias do método, que vão } \\
\text { desde a organização planejada das } \\
\text { equipes até a avaliação entre os } \\
\text { colegas, estimulam a interação e, } \\
\text { consequentemente, a evolução das } \\
\text { equipes. Essa característica especial do }\end{array}$ \\
\hline
\end{tabular}




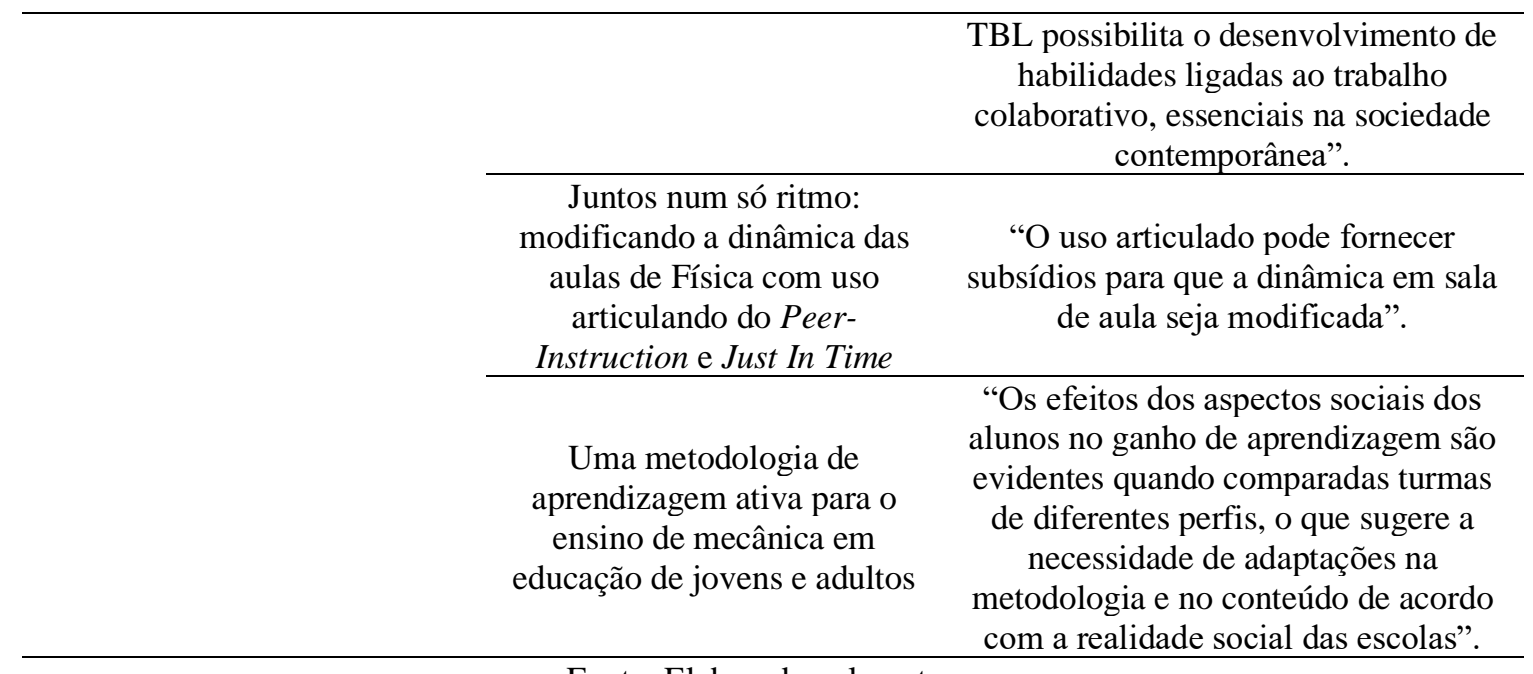

Fonte: Elaborado pelo autor

Após a leitura dos artigos (Tabela 1) foi possível perceber, na análise, a frequência das categorias nas propostas dos trabalhos. Entre as categorias, "Atitude no relacionamento com o conhecimento" foi a mais frequente com $50 \%$ de presença nos trabalhos, evidenciando que as metodologias ativas aparecem de forma que despertam, nos estudantes, atitudes positivas no que tange o relacionamento com a construção do conhecimento. É importante notar que, dentre as metodologias ativas que mais se destacaram nesta categoria, figura o Peer-Instruction e/ou outras metodologias que usam seus elementos. De fato, faz parte da proposta dessa metodologia, criar um ambiente no qual, a partir da interação com os seus pares, os alunos desenvolvam a atitude de questionar, argumentar, refletir e criticar.

Outra categoria que se mostrou frequente foi "Revisão de formas de aprender a realidade". Foi possível encontrar traços dessa categoria em 33.33\% dos trabalhos analisados. Aqui, destacam-se, além do Peer-Instruction, também as metodologias TeamBased Learning, Just-in-Time Teaching e Flipped Classroom. De acordo com os trechos destacados, todas estas metodologias fornecem, aos discentes, possibilidades de uma nova forma de se relacionar e aprender a realidade.

$$
\text { Nas demais categorias }
$$

"Contextualização", "Ser baseado nas experiências do aluno", "Unidade problematizadora", "Projetos de interação das disciplinas" e "Interação dos prontos de vistas ou os discursos das várias disciplinas" (distinguíveis em 11,11\%, 5,55\%, $16,66 \%, 11,11 \%$ e $5,55 \%$ dos trabalhos analisados, respectivamente) -, figuram trabalhos com as metodologias Peer-Instruction, Just-in-Time Teaching, Gamificação, Team-Based Learning, Flipped Classroom, Problem-Based Learning,

Destaque-se o poder de contextualização da metodologia Just-in-Time Teaching, tendo em vista que

\footnotetext{
"a possibilidade do aluno ter contato com o conteúdo antes das aulas é um fator que auxilia na articulação mais adequada do conteúdo com o contexto do aluno..." (SILVA, FIGUEIREDO \& RODRIGUES, 2014).
}

Também é importante destacar o potencial para criar unidades problematizadoras e projetos de interação das disciplinas presente na metodologia Problem-Based Learning. 
Nossos resultados sugerem que todas as metodologias ativas descritas e estudadas nos trabalhos analisados apresentam, pelo menos, uma das características (aqui descritas pelas categorias) que as potencializam como práticas possíveis para uma proposta interdisciplinar de ensino $\mathrm{e}$ aprendizagem, pois proporcionam aos estudantes diversas situações que permitem a vivência e busca pela construção do conhecimento por meio do processo de diálogo, intelectualmente estruturado, entre os mesmos e entre as áreas do saber.

\section{CONSIDERAÇÕES FINAIS}

Com a pesquisa, pode-se entender que as metodologias ativas mostram-se como uma concepção educacional que visa colocar os estudantes como principais agentes de seu aprendizado, pois percebe-se, que através delas é despertado o estímulo à crítica e à reflexão, incentivadas pelo professor que será o responsável a conduzir a aula de forma que propicia ao aluno um aprendizado de forma significativa, uma vez que, a participação dos alunos como sujeitos ativos ocasiona mudanças positivas no processo de ensino e aprendizagem.

Em relação ao desenvolvimento da interdisciplinaridade, concluímos que as metodologias ativas contribuem de forma significativa, pois proporciona aos estudantes situações em que desperta a construção do conhecimento das diversas áreas do saber. No entanto, trabalhar a interdisciplinaridade, não é apenas o professor ser interdisciplinar, mas sim a instituição assumir esse novo paradigma, permitir-se ao novo, possibilitando o mesmo a todos os sujeitos que dela fazem parte (FAZENDA, 2013).
É fato que, apesar de sua inegável importância, a interdisciplinaridade ainda é retórica e não acontece, efetivamente, como ação pedagógica. Essa realidade precisa ser transformada e para isso é necessário que haja no cenário educacional um aumento de produções cientificas que evidenciem o desenvolvimento da interdisciplinaridade na educação básica e em específico no ensino médio.

\section{AGRADECIMENTO}

Agradeço a Coordenação de Aperfeiçoamento de Pessoal de Nível Superior (CAPES) pelo financiamento dos estudos no Programa de Pós-Graduação em Ensino (UERN/UFERSA/IFRN) e assim proporciona apoio a produções acadêmicas.

Todos os autores declararam não haver qualquer potencial conflito de interesses referente a este artigo.

\section{REFERÊNCIAS}

ALVARENGA, A. T.; ALVAREZ, A. M. S.; SOMMERMAN, A.; PHILIPPI JR, A. Interdisciplinaridade e transdisciplinaridade nas tramas da complexidade e desafios aos processos investigativos. In. Práticas da Interdisciplinaridade no Ensino e Pesquisa. Barueri, São Paulo: Manole, 2015, p. $37-89$.

BRASIL. Parâmetros Curriculares Nacionais Ensino Médio: bases legais. Brasília: MEC, 2000. Disponível em: http://portal.mec.gov.br/seb/arquivos/pdf/blegais.pdf . Acesso em: 20 abr. 2019.

BRASIL. MINISTÉRIO DA EDUCAÇÃO. CONSELHO NACIONAL DE EDUCAÇÃO. CÂMARA DE EDUCAÇÃO BÁSICA. Resolução $n^{\circ}$. 2, de 30 de janeiro 2012. Define Diretrizes Curriculares Nacionais para o Ensino Médio. Disponível em: http://portal.mec.gov.br/index.php?option=com_doc man\&view=download\&alias=9917-rceb002-121\&Itemid=30192. Acesso em: 20 abr. 2019. 
BARDIN, L. Análise de conteúdo. São Paulo:

Edições 70, 2011.

COELHO, M. N. Uma comparação entre TeamBased Learning e Peer-Instruction em turmas de Física do Ensino Médio. Revista Ensino Interdisciplinar. Mossoró, v. 4, n. 10, pp. 40-50, 2018.

COELHO, M. N. Metodologias ativas: uma possibilidade para o Ensino Médio. In. Ensino na Educação Básica. Natal: IFRN, 2017, p. 169 - 193.

CASTRO, W. A.; MELO, R. A. Interdisciplinaridade: a trajetória histórica de um conceito. In: X Encontro Regional Nordeste de História Oral. Salvador, 2015. Anais...Salvador, $2015 . \quad$ Disponível em: http://www.nordeste2015.historiaoral.org.br/site/anai scomplementares. Acesso em: 01 jun. 2019.

FAZENDA, I. C. A. Práticas Interdisciplinares na Escola. 13. ed. rev. e ampl. São Paulo: Cortez, 2013.

FAZENDA, I. C. A. Didática e Interdisciplinaridade. Campinas, São Paulo: Papirus, 1998.

FAZENDA, I. C. A. O que é

interdisciplinaridade?. São Paulo: Cortez, 2008.

JAPIASSU, H. A questão da interdisciplinaridade. Texto base da palestra proferida no

Seminário Internacional sobre Reestruturação Curricular, promovido pela Secretaria Municipal de Educação de Porto Alegre, em julho de 1994. Disponível em: http://smeduquedecaxias.rj.gov.br/nead/Biblioteca/F orma\%C3\%A7\%C3\%A30\%20Continuada/Artigos\% 20Diversos/interdisciplinaridade-japiassu.pdf.

Acesso em: 01 jun. 2019.

MORAN, J. Mudando a educação com metodologias ativas. In: Coleção Mídias Contemporâneas. Convergências midiáticas, educação e cidadania: aproximações jovens. Ponta Grossa-PR: UEPG/PROEX, 2015, p. 15 